\title{
Right ventricular remodeling after transapical transcatheter mitral valve implantation for severe mitral regurgitation.
}

\author{
Sara Hungerford ${ }^{1}$, Nicole Bart ${ }^{1}$, Paul Jansz ${ }^{1}$, Sharon Kay ${ }^{2}$, Sam Emmanuel ${ }^{1}$, Mayooran \\ Namasivayam $^{1}$, Gry Dahle ${ }^{3}$, Alison Duncan ${ }^{4}$, Christopher S. Hayward ${ }^{1}$, and David W. M. \\ Muller $^{1}$ \\ ${ }^{1}$ St Vincent's Hospital Sydney \\ ${ }^{2}$ The University of Sydney \\ ${ }^{3}$ Oslo University Hospital \\ ${ }^{4}$ Royal Brompton Hospital
}

October 5, 2020

\begin{abstract}
Background: Transapical transcatheter mitral valve implantation (TMVI) may be a therapeutic option for patients with severe mitral regurgitation (MR) excluded from cardiac surgery due to excessive risk. Common reasons for exclusion from surgery are pulmonary hypertension and right ventricular (RV) dysfunction. The effect of TMVI on RV function has not previously been well-characterized. Objectives: The aim of this study was to examine the procedural and 3-month impact of TMVI on RV hemodynamics and remodeling. Methods: This was a multi-center, retrospective, observational cohort study of patients with $>3+$ MR undergoing TMVI. Pre- and post-TMVI hemodynamics were assessed with right heart catheterization. RV remodeling was assessed at baseline, pre-discharge and at 3-months by echocardiography. Results: Forty-six patients (age $72 \pm 9$ years; 34 men) with [?]3+MR underwent TMVI over a 5-year period. Successful device implantation was achieved in all patients with abolition of $\mathrm{MR}(\mathrm{p}<0.001)$ and reduction in left-ventricular end-diastolic volume $(\mathrm{p}=0.001)$. RV stroke work index increased intra-operatively $(7+-4 \mathrm{~g} / \mathrm{m} /$ beat $/ \mathrm{m} 2$ vs $11+-5 \mathrm{~g} / \mathrm{m} /$ beat $/ \mathrm{m} 2 ; \mathrm{p}<0.001)$. At 3-months there were reductions in severity of tricuspid regurgitation $(\mathrm{TR})(\mathrm{p}<0.001)$ and pulmonary artery systolic pressure (PASP) $(49+-16 \mathrm{mmHg}$ vs $36+-$ $12 \mathrm{mmHg} ; \mathrm{p}<0.001)$, and improvements in RV fractional area change $(28+-7 \%$ vs $34+-9 \%, \mathrm{p}<0.001)$, tricuspid annular plane systolic excursion (TAPSE) (1.0+-0.3 vs $1.5+-0.5 \mathrm{~cm}, \mathrm{p}=0.03)$, and RV free wall longitudinal strain $(-14.2+-5.0 \mathrm{vs}-17.6+-7.3$, $\mathrm{p}=0.05)$. Conclusions: Transapical TMVI results in significant improvement of RV function that is sustained to 3 months as evidenced by reductions in TR severity and PASP, and improvements in RV fractional area change, TAPSE, and RV free wall longitudinal strain.
\end{abstract}

Right ventricular remodeling after transapical transcatheter mitral valve implantation for severe mitral regurgitation.

Short title: Right ventricular remodeling after transcatheter mitral valve implantation.

Author names: Sara Hungerford1,2,3 MBBS, Nicole Bart1,2,3 MBBS PhD, Paul Jansz2,3,4 MBBS PhD, Sharon Kay5,6 BSc MSc PhD, Sam Emmanuel2,3,4 MBBS, Mayooran Namasivayam1,2,3 MBBS, PhD, Gry Dahle7,8 MBBS, Alison Duncan9 MBBS PhD, Christopher Hayward1,2,3 BMedSc MBBS MD, David W.M. Muller1,2,3 MBBS MD.

Institutions: 1) Department of Cardiology, St Vincent's Hospital, Sydney Australia. 2) The University of New South Wales, Sydney Australia. 3) Victor Chang Cardiac Research Institute, Sydney Australia. 4) Department of Cardiothoracic Surgery, St Vincent's Hospital, Sydney Australia. 5) The University of Sydney, 
Sydney Australia. 6) The Kolling Institute, Sydney Australia. 7) Department of Cardiothoracic Surgery, Oslo University Hospital, Oslo Norway. 8) Oslo University, Oslo Norway. 9) Department of Cardiology, Royal Brompton Hospital, London United Kingdom.

Author emails: Sara Hungerford: hungerford.sara@gmail.com; Nicole Bart: nikkibart@gmail.com; Paul Jansz: Paul.Jansz@svha.org.au; Sharon Kay: sharonmkay@gmail.com; Sam Emmanuel: SamEmmanuel@windowslive.com; Mayooran Namasivayam: mjnama@gmail.com; Gry Dahle: g_dahle@hotmail.com; Alison Duncan: A.Duncan@rbht.nhs.uk; Christopher Hayward: cshayward@stvincents.com.au; David Muller: dmuller@stvincents.com.au

Key words: Echocardiography; Mitral regurgitation; Myocardial strain; Right ventricular function; Transcatheter mitral valve implantation.

\section{Address for correspondence:}

Dr Sara Hungerford MBBS and David Muller MBBS, MD

Cardiology Department

St Vincent's Hospital

Victoria St, Darlinghurst NSW 2010 Australia

Phone: +61 416143718

Fax: + 61283822775

Email: dmuller@stvincents.com.au

\section{List of Abbreviations:}

LVEDVI = left ventricular end-diastolic volume indexed

$\mathrm{LVEF}=$ left ventricular ejection fraction

LVESVI = left ventricular end-systolic volume indexed

$\mathrm{MR}=$ mitral regurgitation

PASP $=$ pulmonary artery systolic pressure

RVFAC $=$ right ventricular fractional area change

RVFWLS = right ventricular free wall longitudinal strain

$\mathrm{STE}=$ speckle tracking echocardiography

TAPSE $=$ tricuspid annular plane systolic excursion

TMVI $=$ transapical transcatheter mitral valve implantation

$\mathrm{TR}=$ tricuspid regurgitation

\section{INTRODUCTION:}

Right ventricular (RV) dysfunction in the setting of chronic mitral regurgitation (MR) is common and occurs as a result of intrinsic myocardial dysfunction, maladaptive left ventricular (LV) remodeling, impaired ventricular septal motion, and pericardial constraint imposed by progressive LV volume overload [1-6]. Pulmonary hypertension secondary to severe MR exacerbates RV dysfunction by increasing RV afterload. RV dysfunction may be further exacerbated by tricuspid valve regurgitation (TR), which results from progressive RV and tricuspid annular dilatation. RV dysfunction has important prognostic implications following mitral valve surgery $[7,8]$, and both impaired RV function and pulmonary hypertension are independent predictors of long-term post-operative cardiovascular mortality [2, 3, 9-11]. Patients with impaired RV function 
and significant pulmonary hypertension are frequently excluded from conventional surgical repair but might benefit from transcatheter mitral valve (MV) interventions. Transapical transcatheter mitral valve implantation (TMVI) is an emerging therapeutic alternative to conventional MV surgery for patients deemed to be at prohibitively high risk. The objective of our study was to examine the immediate and short-term impact of transapical TMVI using the Tendyne mitral valve system $[12,13]$ on RV loading and function.

\section{METHODS}

\section{Study population:}

This was a multi-center, retrospective, observational cohort study of one-quarter of worldwide patients who underwent TMVI between October 2014 and October 2019 using the Tendyne system (Tendyne Holdings Roseville, Minnesota) $[12,13]$. The cohort included 41 patients enrolled in the Tendyne Expanded Feasibility Study and 5 patients treated under a Compassionate Use protocol. Patients were considered ineligible for TMVI if they had a pulmonary artery systolic pressure (PASP) $>70 \mathrm{mmHg}$ or severe RV dysfunction. Details of the procedure and patient outcomes at 30-days and 1-year have been described previously [12, 13]. The study was approved by the respective local hospital Ethics Committee. All demographic data were manually extracted from the electronic medical records.

\section{Echocardiography:}

Each patient underwent 2D-transthoracic echocardiogram (TTE) before TMVI, 2D-TTE pre-discharge and further TTEs at 1 and 3-months. Patients were excluded if TTE data were not available or acquired outside the study time period. TTE images were obtained using an EPIQ 7 (Phillips Healthcare, Eindhoven, the Netherlands) or Vivid 95 (GE Medical Systems, Horten, Norway) ultrasound machine. Standardized measurements were performed at the time of image acquisition or offline using local hospital reporting systems in accordance with guidelines from the American Society of Echocardiography [14]. Measurements using 2D-speckle tracing echocardiography (STE) were performed offline using EchoInsight Pro (Epsilon Imaging, Michigan, USA) with a frame rate of at least 30 frames/s (Figure 1).

Patients were stratified into two groups based on the pre-operative LV ejection fraction (EF). LV function was quantified by recording LVEF using the Simpson's biplane method, LV end-diastolic dimension (LVEDD), end-systolic dimension (LVESD), end-diastolic volume (LVEDV), end-systolic volume (LVESV), LV global longitudinal strain (GLS), circumferential and radial strain (Figure 2). Global RV systolic function was recorded qualitatively as a categorical variable (mild, moderate or severe) and quantitatively by: pulmonary artery systolic pressure (PASP), RV fractional area change (RVFAC), RV longitudinal myocardial velocity (RVS'), RV basal diameter, RV free wall longitudinal strain (FWLS) and tricuspid annular plane systolic excursion (TAPSE). RVFWLS was calculated as the systolic peak of the average curve from a 6 -segment ROI after manually excluding the septal segments $[15,16]$ and defined as normal if $<-20 \%[14,17,18]$.

Degree of valvular regurgitation of the mitral and tricuspid valves were recorded qualitatively as categorical variables (mild, moderate, moderate-severe, severe), and in the case of MR, quantitatively by: proximal isovelocity surface area (PISA), regurgitation fraction (RF), end regurgitant orifice area (EROA), regurgitant volume and vena contracta (VC).

All 2D-STE measurements were analyzed offline by two experienced independent observers (SH \& NB). For assessment of intra- and inter-observer variability, each observer was blinded to the other observer's results. Measurements were repeated after a $>4$-week interval by the same observers blinded to the initial measurements and reproducibility was comparable with quaternary centers experienced in the technique (Table 1). 2D-TTE image quality was sufficient to perform volumetric analysis in all 46 patients, but on 41 occasions (41/138; $30 \%$ of all TTEs analyzed), the image quality was insufficient or not available to perform full 2D-STE analysis.

\section{Hemodynamic data:}

Right heart catheterization (RHC) data were collected pre-operatively and shortly after device deployment. 
Collected parameters included right atrial (RA) pressure, PASP, PA diastolic pressure (PADP), mean PA pressure (MPAP), central venous pressure (CVP), cardiac output (CO), cardiac index (CI), stroke volume index (SVI) and RV stroke work index (RVSWI). Overall, 31 of 46 patients (67\%) had complete RHC data for full hemodynamic analysis.

Statistical analysis:

Reporting data was manually entered by an independent observer. All descriptive data are reported as mean \pm SD. A repeated-measures analysis was conducted comparing echocardiographic measures across time. After identification of an overall significant difference, all possible pairwise comparisons were made, and a Tukey adjustment was applied to control the overall type I error rate. A Wilcoxon rank-sum analysis was used to examine the difference between time intervals. Data analysis was performed with SPSS-24 (IBM Corporation, Armonk, New York).

\section{RESULTS}

\section{Baseline characteristics}

Forty-six of the 47 (98\%) patients who underwent TMVI between October 2014 and October 2019 were enrolled in this analysis. The age of the study population was $72 \pm 9$ years ( $74 \%$ males; $\mathrm{n}=34$ ) (Table 2 ). All were New York Heart Association (NYHA) functional classes III or IV. All patients had [?]grade 3+MR before TMVI and most patients (91\%) had secondary/functional MR (predominantly due to ischemic leaflet tethering) (Table 2). In patients with an LVEF 35-50\%, 54\% had an EROA [?]0.4cm2, and in patients with an LVEF [?] $35 \%$, all patients had an EROA [?]0.2cm2. Baseline demographic and TTE characteristics of the study population are reported in Tables 2 and 3.

\section{Hemodynamic data:}

Resting PASP measured invasively immediately before TMVI was elevated ([?]25mmHg) in 29 patients (88\%) (PASP 48+-16mmHg; PADP 26+-8mmHg; MPAP 34+-8mmHg). Although there was no change in PA pressures immediately after TMVI (PASP 48+-13mmHg; PADP 27+-7mmHg; MPAP 35+-9mmHg; $\mathrm{p}=0.18)$ (Table 4), there were immediate increases in contractility as evidenced by an increase in RVSWI (from $7+-4 \mathrm{~g} / \mathrm{m} /$ beat $/ \mathrm{m} 2$ to $11+-5 \mathrm{~g} / \mathrm{m} /$ beat $/ \mathrm{m} 2, \mathrm{p}<0.001$ ) (Figure $3 \mathrm{a}$ ), SVI (from $29+-8 \mathrm{~mL} /$ beat $/ \mathrm{m} 2$ to $34+-11 \mathrm{~mL} / \mathrm{beat} / \mathrm{m} 2, \mathrm{p}<0.001$ ) and $\mathrm{CO}$ (from $3.7+-1.1 \mathrm{~L} / \mathrm{min}$ to $4.6+-1.4 \mathrm{~L} / \mathrm{min}, \mathrm{p}<0.001$ ) (Table 4 ). CVP and HR remained steady (Table 4 ).

\section{Left ventricular remodeling:}

MR was abolished in all patients immediately following TMVI and this was associated with a reduction in $\mathrm{LV}$ volumes. At 3-months no patient had $>1+\mathrm{MR}(\mathrm{n}=46 ; \mathrm{p}<0.001$ vs baseline) (Table 5; Figure 4). Thirty-six patients $(78 \%)$ had a LVEF $<50 \%$ at baseline, and 18 patients $(39 \%)$ had a LVEF [?]35\%. For the entire group, indexed LVEDV (LVEDVI) and indexed LVESV (LVESVI) were elevated pre-operatively (88+$24 \mathrm{~mL} / \mathrm{m} 2$ and $54+-20 \mathrm{~mL} / \mathrm{m} 2$ respectively) (Tables 2 and 3 ), and decreased on discharge to $72+-23 \mathrm{~mL} / \mathrm{m} 2$ $(\mathrm{p}=0.001)$ and $45+-17 \mathrm{~mL} / \mathrm{m} 2(\mathrm{p}=0.03)$, respectively (Table 5; Figure 5). The improvement in LVEDVI was sustained at 3-month follow-up $(70+-40 \mathrm{~mL} / \mathrm{m} 2, \mathrm{p}=0.003)$, but was associated with a small decline in LVEF (40+-10\% vs 36+-15\%; $\mathrm{p}=0.008$ ) (Table 5). There was a non-significant decline in LVGLS, whilst circumferential and radial strain remained steady at 3-months presumably due to the effect of the apical tether (Table 5).

\section{Right ventricular remodeling:}

RV function was impaired at baseline and improved after TMVI. In keeping with improved RVSWI, RVFAC increased from $28+-7 \%$ before TMVI to $33+-8 \%$ at hospital discharge $(\mathrm{p}=0.03)$, and $34+-9 \%$ at 3 -months $(\mathrm{p}<0.001$ vs baseline) (Table 5; Figure 3b). TAPSE increased from $1.0+-0.3 \mathrm{~cm}$ before TMVI to $1.5+-0.5 \mathrm{~cm}$ at 3-months $(\mathrm{p}=0.03)$. RVFWLS improved from $-14.2+-5.0 \%$ before TMVI to $-17.6+-7.3 \%$ at 3 -months $(\mathrm{p}=0.05)$, whilst there was a non-significant trend towards improved RVS' (Table 5). 
There was a significant reduction in RV length post TMVI $(\mathrm{p}=0.04)$ with an associated reduction in TR severity. At discharge, 41 (89\%) patients had no detectable/trivial or mild TR ( $\mathrm{p}<0.001)$, an improvement that was sustained at 3-month follow-up (Table 5; Figure 4). PASP decreased significantly (from 49+$16 \mathrm{mmHg}$ to $36+-12 \mathrm{mmHg}$ at 3 -months; $\mathrm{p}<0.001$ ) (Table 5; Figure 3c).

Right ventricular remodeling stratified for left ventricular function:

RV dysfunction was prominent in the 18 patients with baseline LVEF <35\%: RVFAC 25+-9\%; RVFWLS 13+-5\%; RVS' $6.5+-2.1 \mathrm{~cm} / \mathrm{s}$; TAPSE 1.3+-0.5cm; PASP 48+-14mmHg) (Table 6). After TMVI, RV function improved at 3 -months, with an increase in RVFAC (to $35+-11 \%, \mathrm{p}=0.03$ ) and reduction in PASP (to $32+-$ $9 \mathrm{mmHg}, \mathrm{p}=0.01$, Table 6). There were non-significant increases in RVFWLS, RVS' and TAPSE (Table $6)$.

Patients with a LVEF [?]35\% had less severe RV dysfunction before TMVI compared to patients with a LVEF $<35 \%$ (RVFAC 29+-5\%; RVFWLS -15+-5\%; RVS' 7.9+-2.8cm/s; TAPSE 1.4+-0.4cm; PASP 47+-17mmHg) (Table 6). In this group, RVFAC also increased to $35+-8 \%(\mathrm{p}=0.01)$ and PASP decreased to $34+-12 \mathrm{mmHg}$ $(\mathrm{p}=0.01)$ 3-months after TMVI (Table 6). There were non-significant increases in RVFWLS and TAPSE (Table 6).

\section{DISCUSSION}

The findings of this study, the first to evaluate RV remodeling after TMVI in patients excluded from conventional cardiac surgery due to excessive risk, can be summarized as follows: TMVI using the transapically tethered Tendyne mitral valve system resulted in (i) abolition of MR with an associated immediate increase in SVI and a reduction in LV volumes; (ii) an immediate increase in RVSWI with an improvement in RV contractile performance as measured by RVFAC, TAPSE, RVFWLS and RVS'; (iii) a reduction in PASP and severity of TR at 3-months. The extent of improvement in RV remodeling at 3-months in the group with severe LV dysfunction was similar to that of the group with less severe LV and RV dysfunction at baseline (Figure 6; Video 1 and 2).

Intrinsic myocardial dysfunction:

The volume overload of chronic MR results in progressive eccentric LV hypertrophy and an eventual decline in contractile performance. RV dysfunction in patients with chronic MR is often overlooked but occurs as a consequence of left-sided heart disease. RV dysfunction has previously been shown to occur in approximately $30 \%$ of patients referred for MV repair surgery [1-3], and is found in up to $50 \%$ of patients with severe MR and LV dysfunction [1-3]. More than three-quarters of patients enrolled in our study had significant RV dysfunction pre-operatively (RVFAC $<35 \%$ and RVFWLS [?]20\%), and of the patients who had detectable TR, all had a PASP [?]25mmHg by echocardiography. The prevalence of pre-operative RV dysfunction has been poorly described in transcatheter treated patients to date $[19,20]$, and is significantly higher in our population than in a previous surgical MV repair series [3]. This finding is unsurprising given that our cohort was deemed too high-risk for conventional mitral valve surgery, but nevertheless highlights the need to monitor for early or late RV dysfunction and/or failure as a consequence of abrupt LV unloading after Tendyne TMVI.

\section{$L V$ unloading and $R V$ remodeling:}

LV chamber dilatation, in association with residual or uncorrected MR, increases the pericardial constraints on the right ventricle and impairs RV contractile performance [21]. Following surgical MV repair, a reduction in LV volumes has been associated with an improvement in RV function [3]. As has previously been reported, our data demonstrated that Tendyne TMVI resulted in an abolition of MR and a significant reduction in LV volumes $[12,13]$. TMVI induced LV unloading was maximal in the period immediately following implantation, however a gradual re-dilatation of the left ventricle was observed in those patients with severe pre-existing LV dysfunction (Table 5; Figures 4 and 5). We also observed a post-operative reduction in LVEF which is consistent with what has previously been described in surgical and transcatheter repair studies due to the unmasking of the true intrinsic myocardial function of the volume-loaded LV through elimination of 
MR. Regardless, the abolition of MR and concomitant reduction in LV volumes, resulted in an immediate and sustained improvement in RV function as determined invasively post-deployment by RVSWI and noninvasively by RVFAC on echocardiography ( $<<0.001$; Table 4 and Figure 3$)$. The improvement in RV function was seen both in patients with moderate $(\mathrm{p}=0.02)$ and severe $(\mathrm{p}=0.02) \mathrm{LV}$ dysfunction.

Improved $L V$ septal function and $R V$ remodeling:

Chronic MR is frequently associated with impaired ventricular septal motion. The contribution of septal contraction to RV systolic function ranges from $24 \%$ in a normal RV to $35 \%$ in RV dysfunction [22, 23]. Interventricular septal contraction is able to maintain RV function and cardiac output despite RV freewall impairment [3, 22-24]. In this study, LV radial and circumferential strain remained steady at 3-months despite an overall decline in other measurements of LV contractile performance including EF and GLS (Table 5). This observation might suggest a redistribution of LV contractile load from the apex to the base of the heart, possibly related to the mechanical effect of the tether and its fixation to an apical pad. Similarly, more modest changes in RV longitudinal and annular function relative to RVFAC are observed in our study. This suggests that in addition to improvement in intrinsic myocardial contractility of the RV free wall, it is the exaggerated movement of the septum, possibly induced by the tether and apical pad, that contributes to an immediate improvement in overall RV function and warrants future evaluation.

\section{Indirect consequences of $M R$ correction:}

RV dysfunction in the setting of MR may be further exacerbated by the presence of TR which occurs due to progressive RV and tricuspid annular dilatation. While the prognostic importance of TR following surgical and transcatheter mitral repair is well known [25], relatively little has been reported on the impact of mitral interventions on severity of TR. In one study of surgical mitral repair for ischemic MR, $>2+\mathrm{TR}$ was present in $30 \%$ of patients pre-operatively. Post-operatively, there was little change in TR severity, irrespective of whether or not tricuspid annuloplasty had been performed [26]. Conversely, in the COAPT trial [27], at 2 -year follow-up, $>2+\mathrm{TR}$ was less frequent in the device group compared with the control group (49.9\% vs $81.0 \%$; HR $0.43,95 \%$ CI: $0.25,0.74)$. Our study demonstrated a significant reduction in overall TR burden which was sustained to 3-months. Pulmonary hypertension secondary to severe MR is also known to exacerbate RV dysfunction by increasing RV afterload. In our study, there was a progressive reduction in PASP 3-months after TMVI on echocardiography as we might have expected (Table 5).

\section{Study limitations:}

Our study relied on echocardiographic image quality for assessment of RV systolic function. Sub-optimal image quality or tracking of the endocardial border occurred most commonly pre-discharge, due to the difficulty in obtaining an adequate dedicated RV apical four-chamber view in the presence of a recent left lateral thoracotomy scar and surgical dressings. A cutoff value of $-20 \%$ for abnormal RVFWLS was used for this study (derived from vendor specific data). We acknowledge that one of the most important and widely discussed limitations of 2D-STE remains inter-vendor variability [28, 29]. Nevertheless, our interand intra-observer intra-class coefficients were comparable to 2D-STE data from other high-volume centers.

\section{CONCLUSIONS:}

RV systolic dysfunction is a frequent finding in patients referred for mitral valve surgery and is both a direct and indirect consequence of LV volume overload. Tendyne TMVI resulted in an immediate improvement in RV function, most likely due to abolition of MR with an associated reduction in LV volumes and reduction in PASP. The preservation of circumferential and radial strain despite an abrupt reduction in LV volume loading, raises the possibility that the apical tether redistributes LV contractile forces and enhances the interventricular septal contribution to RV function. Further longitudinal studies of larger cohorts are needed to confirm and extend our results.

\section{REFERENCES:}

1. Le Tourneau, T., et al., Imaging and modern assessment of the right ventricle. Minerva Cardioangiol, 
2011. 59 (4): p. 349-73.

2. Le Tourneau, T., et al., Echocardiography predictors and prognostic value of pulmonary artery systolic pressure in chronic organic mitral regurgitation. Heart, 2010. 96 (16): p. 1311-7.

3. Le Tourneau, T., et al., Right ventricular systolic function in organic mitral regurgitation: impact of biventricular impairment.Circulation, 2013. 127 (15): p. 1597-608.

4. Morrison, D., et al., The effect of pulmonary hypertension on systolic function of the right ventricle. Chest, 1983. 84 (3): p. 250-7.

5. Alexopoulos, D., et al., Isolated chronic mitral regurgitation with preserved systolic left ventricular function and severe pulmonary hypertension. J Am Coll Cardiol, 1989. 14 (2): p. 319-22.

6. Barbieri, A., et al., Prognostic and therapeutic implications of pulmonary hypertension complicating degenerative mitral regurgitation due to flail leaflet: a multicenter long-term international study. Eur Heart J, 2011. 32 (6): p. 751-9.

7. Borer, J.S., C. Hochreiter, and S. Rosen, Right ventricular function in severe non-ischaemic mitral insufficiency. Eur Heart J, 1991. 12 Suppl B : p. 22-5.

8. Hochreiter, C., et al., Mitral regurgitation: relationship of noninvasive descriptors of right and left ventricular performance to clinical and hemodynamic findings and to prognosis in medically and surgically treated patients. Circulation, 1986. 73 (5): p. 900-12.

9. Pandis, D., et al., Assessment of longitudinal myocardial mechanics in patients with degenerative mitral valve regurgitation predicts postoperative worsening of left ventricular systolic function.J Am Soc Echocardiogr, 2014. 27 (6): p. 627-38.

10. Song, J.M., et al., Echocardiographic predictors of left ventricular function and clinical outcomes after successful mitral valve repair: conventional two-dimensional versus speckle-tracking parameters. Ann Thorac Surg, 2011. 91 (6): p. 1816-23.

11. Witkowski, T.G., et al., Global longitudinal strain predicts left ventricular dysfunction after mitral valve repair. Eur Heart J Cardiovasc Imaging, 2013. 14 (1): p. 69-76.

12. Muller, D.W.M., et al., Transcatheter Mitral Valve Replacement for Patients With Symptomatic Mitral Regurgitation: A Global Feasibility Trial. J Am Coll Cardiol, 2017. 69 (4): p. 381-391.

13. Sorajja, P., et al., Initial Feasibility Study of a New Transcatheter Mitral Prosthesis: The First 100 Patients. J Am Coll Cardiol, 2019. 73 (11): p. 1250-1260.

14. Lang, R.M., et al., Recommendations for cardiac chamber quantification by echocardiography in adults: an update from the American Society of Echocardiography and the European Association of Cardiovascular Imaging. Eur Heart J Cardiovasc Imaging, 2015.16 (3): p. 233-70.

15. Nishimura, R.A., et al., 2014 AHA/ACC guideline for the management of patients with valvular heart disease: a report of the American College of Cardiology/American Heart Association Task Force on Practice Guidelines. J Thorac Cardiovasc Surg, 2014. 148 (1): p. e1-e132.

16. Nishimura, R.A., et al., 2017 AHA/ACC Focused Update of the 2014 AHA/ACC Guideline for the Management of Patients With Valvular Heart Disease: A Report of the American College of Cardiology/American Heart Association Task Force on Clinical Practice Guidelines. J Am Coll Cardiol, 2017. 70 (2): p. 252-289.

17. Rudski, L.G., et al., Guidelines for the echocardiographic assessment of the right heart in adults: a report from the American Society of Echocardiography endorsed by the European Association of Echocardiography, a registered branch of the European Society of Cardiology, and the Canadian Society of Echocardiography. J Am Soc Echocardiogr, 2010. 23 (7): p. 685-713; quiz 786-8. 
18. Vitarelli, A., et al., Assessment of Biventricular Function by Three-Dimensional Speckle-Tracking Echocardiography in Secondary Mitral Regurgitation after Repair with the MitraClip System. J Am Soc Echocardiogr, 2015. 28 (9): p. 1070-82.

19. Obadia, J.F., et al., Percutaneous Repair or Medical Treatment for Secondary Mitral Regurgitation. N Engl J Med, 2018.379 (24): p. 2297-2306.

20. Stone, G.W., et al., Transcatheter Mitral-Valve Repair in Patients with Heart Failure. N Engl J Med, 2018. 379 (24): p. 2307-2318.

21. Santamore, W.P. and L.J. Dell'Italia, Ventricular interdependence: significant left ventricular contributions to right ventricular systolic function. Prog Cardiovasc Dis, 1998.40 (4): p. 289-308.

22. Klima, U., J.L. Guerrero, and G.J. Vlahakes, Contribution of the interventricular septum to maximal right ventricular function. Eur J Cardiothorac Surg, 1998. 14 (3): p. 250-5.

23. Klima, U.P., et al., Determinants of maximal right ventricular function: role of septal shift. J Thorac Cardiovasc Surg, 2002.123 (1): p. 72-80.

24. Hoffman, D., et al., Left-to-right ventricular interaction with a noncontracting right ventricle. J Thorac Cardiovasc Surg, 1994.107 (6): p. 1496-502.

25. Sorajja, P., et al., Outcomes With Transcatheter Mitral Valve Repair in the United States: An STS/ACC TVT Registry Report. J Am Coll Cardiol, 2017. 70 (19): p. 2315-2327.

26. Matsunaga, A. and C.M. Duran, Progression of tricuspid regurgitation after repaired functional ischemic mitral regurgitation.Circulation, 2005. 112 (9 Suppl): p. I453-7.

27. Asch, F.M., et al., Echocardiographic Outcomes After Transcatheter Leaflet Approximation in Patients With Secondary Mitral Regurgitation: The COAPT Trial. J Am Coll Cardiol, 2019.74 (24): p. 2969-2979.

28. Takigiku, K., et al., Normal range of left ventricular 2-dimensional strain: Japanese Ultrasound Speckle Tracking of the Left Ventricle (JUSTICE) study. Circ J, 2012. 76 (11): p. 2623-32.

29. Risum, N., et al., Variability of global left ventricular deformation analysis using vendor dependent and independent two-dimensional speckle-tracking software in adults. J Am Soc Echocardiogr, 2012. 25 (11): p. 1195-203.

Figure 1: TTE apical RV chamber view and sample assessment worksheet.

Abbreviations: $\mathrm{LA}=$ left atrium; $\mathrm{LV}=$ left ventricle; $\mathrm{RA}=$ right atrium; $\mathrm{RV}=$ right ventricle; $\mathrm{RVFAC}$ $=$ right ventricular fractional area change; $\mathrm{S}^{\prime}=\mathrm{RV}$ longitudinal myocardial velocity; TAPSE $=$ tricuspid annular plane systolic excursion; TTE $=$ transthoracic echocardiogram.

Figure 2: TTE and cardiac CT images of Tendyne TMVI.

Top: (Left) TTE four-chamber view demonstrating Tendyne TMVI and apical tether; (Right) cardiac CT four-chamber view demonstrating Tendyne TMVI and apical tether.

Bottom: (Left) TTE parasternal long axis view demonstrating Tendyne TMVI and apical tether; (Right) cardiac CT apical two-chamber view demonstrating Tendyne TMVI and apical tether. CT images courtesy of Dr James Otton.

Abbreviations: $\mathrm{CT}=$ computed tomography; TTE $=$ transthoracic echocardiogram; TMVI $=$ transcatheter mitral valve implantation.

Figure 3: RV hemodynamics and remodeling.

1. Improvement in RVSWI post-device deployment.

2. Change in RVFAC from baseline to pre-discharge and 3-months.

3. Decrease in pulmonary artery systolic pressure to 3 -months. 
Abbreviations: RVFAC $=$ right ventricular fractional area change; RVSWI $=$ right ventricular stroke work index.

Figure 4: Comparison of pre- and post- operative MR and TR.

Figure 4 (top): Bar chart comparison of pre- and post-operative MR following TMVI. All patients had [?] $3+\mathrm{MR}$ pre-operatively. There was a significant reduction in MR pre-discharge $(\mathrm{p}<0.001)$ and at 3 months $(\mathrm{p}<0.001)$.

Figure 4 (bottom): Bar chart comparison of pre- and post-operative TR following TMVI. There was an increase in patients with nil/mild TR post-operatively from $65 \%$ to $89 \%$ post-operatively and at 3 $\operatorname{months}(\mathrm{p}<0.001)$.

Abbreviations: $\mathrm{MR}=$ mitral regurgitation; $\mathrm{TMVI}=$ transcatheter mitral valve implantation; $\mathrm{TR}=$ tricuspid regurgitation.

Figure 5: Comparison of pre- and post-operative LV volumes.

Comparison of LVEDVI and LVESVI pre- and post-TMVI. There was an immediate reduction in both values.

Abbreviations: LVEDVI = left ventricular end diastolic volume indexed; LVESVI $=$ left ventricular end systolic volume indexed; $L V=$ left ventricular; $M R=$ mitral regurgitation; TMVI $=$ transcatheter mitral valve implantation.

Figure 6: Graphical Abstract

Graphical abstract: (Top Left) TTE demonstrating a dilated LV. (Top Middle) 3D TOE of a MV coaptation defect at end-systole. (Middle Left) CT image of Tendyne TMVI. (Left lower) TTE with colour Doppler showing correction of MR following Tendyne TMVI.

Abbreviations: $\mathrm{AV}=$ aortic valve; $\mathrm{MR}=$ mitral regurgitation; $\mathrm{MV}=$ mitral valve; $\mathrm{PASP}=$ pulmonary artery systolic pressure; RV = right ventricular; RVSWI = right ventricular stroke work index; TOE = transesophageal echocardiogram; TTE $=$ transthoracic echocardiogram; TMVI $=$ transcatheter mitral valve implantation.

\section{TABLES}

Table 1: Inter- and intra-class coefficients

\begin{tabular}{|c|c|c|c|}
\hline & Intraclass correlation & $\begin{array}{l}95 \% \text { Confidence interval } \\
\text { Lower bound-Upper } \\
\text { bound }\end{array}$ & $P$ value \\
\hline $\begin{array}{l}\text { RV FWLS Single } \\
\text { Measures Average } \\
\text { Measures }\end{array}$ & 0.8710 .931 & $\begin{array}{l}0.741-0.9380 .851- \\
0.968\end{array}$ & $\mathrm{P}<0.001 \mathrm{P}<0.001$ \\
\hline
\end{tabular}

Table 1 shows excellent inter-rater reliability, with an intraclass correlation of 0.931 (95\% CI $0.85-0.97$ ), $\mathrm{p}<0.01$.

Abbreviations: RVFWLS $=$ right ventricular free wall longitudinal strain.

Table 2: Pre-operative demographic characteristics of study population

\begin{tabular}{ll}
\hline & $(\mathrm{n}=46)$ \\
\hline Age $($ years $)$, mean \pm SD & $72 \pm 9$ \\
Height $(\mathrm{cm})$, mean \pm SD & $171 \pm 9$ \\
Weight $(\mathrm{kg})$, mean \pm SD & $77 \pm 16$
\end{tabular}




\begin{tabular}{|c|c|}
\hline & $(\mathrm{n}=46)$ \\
\hline $\begin{array}{l}\text { BSA }\left(\mathrm{m}^{2}\right), \text { mean } \pm \mathrm{SD} \\
\text { Sex }\end{array}$ & $1.9 \pm 0.2$ \\
\hline Male, n $(\%)$ & $34(74 \%)$ \\
\hline Female, n (\%) & $12(26 \%)$ \\
\hline \multicolumn{2}{|l|}{ Race } \\
\hline White, n (\%) & $44(96 \%)$ \\
\hline COPD, n $(\%)$ & $2(4 \%)$ \\
\hline Creatinine $(\mu \mathrm{mol} / \mathrm{L})$, mean $\pm \mathrm{SD}$ & $130 \pm 59$ \\
\hline eGFR $(\mathrm{mL} / \mathrm{min})$, mean $\pm \mathrm{SD}$ & $53 \pm 20$ \\
\hline NT-proBNP $(n g / L)$, mean \pm SD & $3447 \pm 3148$ \\
\hline Heart rate $(\mathrm{bpm})$, mean $\pm \mathrm{SD}$ & $74 \pm 13$ \\
\hline \multicolumn{2}{|l|}{ Cardiovascular history } \\
\hline Atrial fibrillation & $38(83 \%)$ \\
\hline NYHA class $3-4$ & $46(100 \%)$ \\
\hline Hypertension & $32(70 \%)$ \\
\hline Coronary artery disease & $33(72 \%)$ \\
\hline \multicolumn{2}{|l|}{ MR mechanism } \\
\hline Primary, n (\%) & $4(9 \%)$ \\
\hline Secondary/functional, n (\%) & $42(91 \%)$ \\
\hline \multicolumn{2}{|l|}{ Medications } \\
\hline ACE inhibitors, n (\%) & $30(65 \%)$ \\
\hline Beta-blockers, n (\%) & $34(74 \%)$ \\
\hline Digoxin, n (\%) & $5(11 \%)$ \\
\hline Diuretics, n (\%) & $41(89 \%)$ \\
\hline MRA, n (\%) & $26(57 \%)$ \\
\hline ARNI, n (\%) & $1(2 \%)$ \\
\hline $\mathrm{CRT}, \mathrm{n}(\%)$ & $7(15 \%)$ \\
\hline \multicolumn{2}{|l|}{ Function } \\
\hline STS-PROM, mean \pm SD & $11 \pm 8$ \\
\hline $6 \mathrm{MWT}$, mean $\pm \mathrm{SD}$ & $284 \pm 138$ \\
\hline
\end{tabular}

Abbreviations: $\mathrm{ACE}=$ angiotensin converting enzyme; ARNI = angiotensin receptor neprilysin inhibitor; $\mathrm{BSA}=$ Body Surface Area using Mosteller formula; CRT = cardiac resynchronization therapy; MRA = mineralocorticoid receptor antagonist; NT-proBNP $=$ N-terminal prohormone brain natriuretic peptide; NYHA = New York Heart Association; STS-PROM = Society of Thoracic Surgery predicted risk of mortality; $6 \mathrm{MWT}=$ six-minute walk test.

Table 3: Pre-operative TTE characteristics of the study population.

\begin{tabular}{ll}
\hline & $(\mathrm{n}=46)$ \\
\hline LV function & \\
LV EF \pm SD $(\%)$ & $40 \pm 10$ \\
LVEDD \pm SD $(\mathrm{mm})$ & $60 \pm 6$ \\
LVESD \pm SD $(\mathrm{mm})$ & $46 \pm 8$ \\
LV EDV $\pm \mathrm{SD}(\mathrm{mL})$ & $166 \pm 52$ \\
LV ESV $\pm \mathrm{SD}(\mathrm{mL})$ & $103 \pm 43$ \\
LV EDVI $\pm \mathrm{SD}\left(\mathrm{mL} / \mathrm{m}^{2}\right)$ & $88 \pm 24$ \\
LV ESVI $\pm \mathrm{SD}\left(\mathrm{mL} / \mathrm{m}^{2}\right)$ & $54 \pm 20$ \\
MV E' Velocity $(\mathrm{m} / \mathrm{s})$ & $118 \pm 31$
\end{tabular}




\begin{tabular}{|c|c|}
\hline & $(\mathrm{n}=46)$ \\
\hline MV E' deceleration time $(\mathrm{m} / \mathrm{sec})$ & $154 \pm 68$ \\
\hline LV global longitudinal strain (\%) & $-9.6 \pm 3$ \\
\hline LV circumferential strain (\%) & $-13.4 \pm 5.3$ \\
\hline $\mathrm{LV}$ radial strain $(\%)$ & $6.5 \pm 4.8$ \\
\hline \multicolumn{2}{|l|}{ Mitral Regurgitation } \\
\hline Moderate-Severe, n (\%) & $10(22 \%)$ \\
\hline Severe, n (\%) & $36(78 \%)$ \\
\hline PISA radius $(\mathrm{cm} / \mathrm{s})$ & $0.8 \pm 0.3$ \\
\hline Regurgitant fraction (\%) & $62 \pm 48$ \\
\hline Regurgitant orifice area $\left(\mathrm{cm}^{2}\right)$ & $0.52 \pm 0.45$ \\
\hline Regurgitant volume (mL/beat) & $74 \pm 42$ \\
\hline Vena contracta $(\mathrm{cm})$ & $0.8 \pm 0.3$ \\
\hline \multicolumn{2}{|l|}{ Tricuspid regurgitation } \\
\hline Nil-trivial, n (\%) & $10(22 \%)$ \\
\hline Mild, n (\%) & $20(43 \%)$ \\
\hline Moderate, n (\%) & $9(20 \%)$ \\
\hline Moderate-Severe, n (\%) & $5(11 \%)$ \\
\hline Severe, n (\%) & $2(4 \%)$ \\
\hline \multicolumn{2}{|l|}{ RV function } \\
\hline $\operatorname{PASP}(\mathrm{mmHg}) \pm \mathrm{SD}$ & $49 \pm 16$ \\
\hline $\mathrm{RV}$ FAC $(\%)$, mean $\pm \mathrm{SD}$ & $28 \pm 7$ \\
\hline $\mathrm{RV}$ base $(\mathrm{cm})$, mean $\pm \mathrm{SD}$ & $4.2 \pm 0.7$ \\
\hline $\mathrm{RV}$ mid $(\mathrm{cm})$, mean $\pm \mathrm{SD}$ & $3.6 \pm 1.0$ \\
\hline $\mathrm{RV}$ length $(\mathrm{cm})$, mean $\pm \mathrm{SD}$ & $7.4 \pm 1.2$ \\
\hline RV FWLS (\%), mean \pm SD & $-14.2 \pm 5.0$ \\
\hline 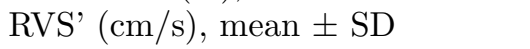 & $7.4 \pm 2.6$ \\
\hline TAPSE $(\mathrm{cm})$, mean \pm SD & $1.0 \pm 0.3$ \\
\hline
\end{tabular}

Abbreviations: $\mathrm{FAC}=$ fractional area change; FWLS $=$ free wall longitudinal strain; $\mathrm{LV}=$ left ventricular; LVEDD = left ventricular end diastolic dimension; LVEDV = left ventricular end diastolic volume; LVEDVI $=$ left ventricular end diastolic volume indexed; LVEF = left ventricular ejection fraction; LVESD = left ventricular end systolic dimension; LVESV = left ventricular end systolic volume; LVESVI = left ventricular end systolic volume indexed; $\mathrm{MR}=$ mitral regurgitation; $\mathrm{MV}=$ mitral valve; $\mathrm{PASP}=$ pulmonary artery systolic pressure; RV = right ventricular; TAPSE $=$ tricuspid annular plane systolic excursion; $\mathrm{TR}=$ tricuspid regurgitation.

Table 4: Intra-procedural right heart catheterization.

\begin{tabular}{llll}
\hline & Pre-Deployment & Post-Deployment & Pre- to Post-Deployment \\
\hline & $(\mathrm{n}=46)$ & $(\mathrm{n}=31)$ & \\
CVP $(\mathrm{mmHg})$ & $15 \pm 5.2$ & $16 \pm 6$ & $\mathrm{p}=0.47$ \\
PASP (mmHg) & $48 \pm 16$ & $48 \pm 13$ & $\mathrm{p}=0.26$ \\
PADP (mmH) & $26 \pm 8$ & $27 \pm 7$ & $\mathrm{p}=0.14$ \\
MPAP (mmHg) & $34 \pm 8$ & $35 \pm 9$ & $\mathrm{p}=0.18$ \\
CO $(\mathrm{L} / \mathrm{min})$ & $3.7 \pm 1.1$ & $4.6 \pm 1.4$ & $\mathbf{p}<\mathbf{0 . 0 0 1}$ \\
CI $(\mathrm{L} / \mathrm{min} / \mathrm{m})$ & $1.9 \pm 0.5$ & $2.4 \pm 0.7$ & $\mathbf{p}<\mathbf{0 . 0 0 1}$ \\
Stroke volume index $\left(\mathrm{mL} /\right.$ beat $\left./ \mathrm{m}^{\mathbf{2}}\right)$ & $29 \pm 9$ & $34 \pm 11$ & $\mathbf{p}<\mathbf{0 . 0 0 1}$ \\
RVSWI $\left(\mathrm{g} / \mathrm{m} /\right.$ beat $\left./ \mathrm{m}^{\mathbf{2}}\right)$ & $7 \pm 4$ & $11 \pm 5$ & $\mathbf{p}<\mathbf{0 . 0 0 1}$ \\
PAPI & $1.4 \pm 0.8$ & $1.5 \pm 0.8$ & $\mathrm{p}=0.20$ \\
\hline
\end{tabular}


All values are mean \pm standard deviation.

Abbreviations: CI indicates cardiac index; CO indicates cardiac output; CVP indicates central venous pressure; MPAP indicates mean pulmonary artery pressure; PADP indicates pulmonary artery diastolic pressure; PAPI indicates pulmonary artery pulsatility index; PASP indicates pulmonary artery systolic pressure; RVSWI indicates right ventricular stroke work index.

Table 5: Comparison of pre-, post- and short-term TTE characteristics of the study population

\begin{tabular}{|c|c|c|c|c|}
\hline & Pre- & Pre-discharge & 1 to 3 months & $\begin{array}{l}\text { Pre- to } \\
\text { Pre-discharge; Pre- } \\
\text { to } 3 \text {-months }\end{array}$ \\
\hline LV function & & $(\mathrm{n}=46)$ & $(\mathrm{n}=46)$ & \\
\hline $\mathrm{LV} \mathrm{EF} \pm \mathrm{SD}(\%)$ & $40 \pm 10$ & $35 \pm 12$ & $36 \pm 15$ & $\begin{array}{l}\mathrm{p}=0.001 ; \mathrm{p}= \\
0.008\end{array}$ \\
\hline $\begin{array}{l}\mathrm{LV} \text { EDD } \pm \mathrm{SD} \\
(\mathrm{mm})\end{array}$ & $60 \pm 6$ & $60 \pm 8$ & $60 \pm 8$ & $\begin{array}{l}\mathrm{p}=0.510 ; \mathrm{p}= \\
0.732\end{array}$ \\
\hline $\begin{array}{l}\mathrm{LV} \text { ESD } \pm \mathrm{SD} \\
(\mathrm{mm})\end{array}$ & $46 \pm 8$ & $51 \pm 10$ & $50 \pm 11$ & $\begin{array}{l}\mathrm{p}=0.001 ; \mathrm{p}= \\
0.008\end{array}$ \\
\hline $\begin{array}{l}\mathrm{LV} \text { EDV } \pm \mathrm{SD} \\
(\mathrm{mL})\end{array}$ & $166 \pm 52$ & $133 \pm 44$ & $147 \pm 72$ & $\begin{array}{l}\mathbf{p}=\mathbf{0 . 0 0 1 ;} p= \\
0.062\end{array}$ \\
\hline $\begin{array}{l}\mathrm{LV} \mathrm{ESV} \pm \mathrm{SD} \\
(\mathrm{mL})\end{array}$ & $103 \pm 43$ & $84 \pm 32$ & $102 \pm 66$ & $\begin{array}{l}\mathbf{p}=\mathbf{0 . 0 2 1} ; \mathrm{p}= \\
0.939\end{array}$ \\
\hline $\begin{array}{l}\mathrm{LV} \text { EDVI } \pm \mathrm{SD} \\
\left(\mathrm{mL} / \mathrm{m}^{2}\right)\end{array}$ & $88 \pm 24$ & $72 \pm 23$ & $70 \pm 40$ & $\begin{array}{l}\mathrm{p}=0.001 ; \mathrm{p}= \\
0.003\end{array}$ \\
\hline $\begin{array}{l}\mathrm{LV} \text { ESVI } \pm \mathrm{SD} \\
\left(\mathrm{mL} / \mathrm{m}^{2}\right)\end{array}$ & $54 \pm 20$ & $45 \pm 17$ & $48 \pm 35$ & $\begin{array}{l}\mathbf{p}=\mathbf{0 . 0 3 3 ;} \mathrm{p}= \\
0.328\end{array}$ \\
\hline $\begin{array}{l}\mathrm{LV} \text { global } \\
\text { longitudinal } \\
\text { strain }(\%)\end{array}$ & $-9.6 \pm 3$ & $-9.4 \pm 4.4$ & $-8.2 \pm 4.7$ & $\begin{array}{l}\mathrm{p}=0.446 ; \mathrm{p}= \\
0.059\end{array}$ \\
\hline $\begin{array}{l}\mathrm{LV} \\
\text { circumferential } \\
\text { strain }(\%)\end{array}$ & $-13.4 \pm 5.3$ & $-16.2 \pm 8.9$ & $-14.1 \pm 6.2$ & $\begin{array}{l}\mathrm{p}=0.586 ; \mathrm{p}= \\
0.878\end{array}$ \\
\hline $\begin{array}{l}\mathrm{LV} \text { radial strain } \\
(\%)\end{array}$ & $6.5 \pm 4.8$ & $5.5 \pm 8.9$ & $6.5 \pm 9.2$ & $\begin{array}{l}\mathrm{p}=0.443 ; \mathrm{p}= \\
0.213\end{array}$ \\
\hline \multicolumn{5}{|l|}{ Mitral } \\
\hline Nil-trivial, n (\%) & $0(0 \%)$ & $41(89 \%)$ & $42(91 \%)$ & $\mathrm{p}<0.001$ \\
\hline Mild, n (\%) & $0(0 \%)$ & $5(11 \%)$ & $4(9 \%)$ & $\mathrm{p}=\mathrm{N} / \mathrm{S}$ \\
\hline Moderate, n (\%) & $0(0 \%)$ & $0(0 \%)$ & $0(0 \%)$ & \\
\hline $\begin{array}{l}\text { Moderate-Severe, } \\
\mathrm{n}(\%)\end{array}$ & $10(22 \%)$ & $0(0 \%)$ & $0(0 \%)$ & $\mathrm{p}<0.001$ \\
\hline $\begin{array}{l}\text { Severe, n (\%) } \\
\text { Tricuspid } \\
\text { Regurgitation }\end{array}$ & $36(78 \%)$ & $0(0 \%)$ & $0(0 \%)$ & \\
\hline Nil-Trivial, n (\%) & $10(22 \%)$ & $18(39 \%)$ & $18(39 \%)$ & $\mathrm{p}<0.001$ \\
\hline Mild, n (\%) & $20(43 \%)$ & $23(50 \%)$ & $23(50 \%)$ & \\
\hline Moderate n (\%) & $9(20 \%)$ & $0(0 \%)$ & $0(0 \%)$ & $\mathrm{p}<0.001$ \\
\hline $\begin{array}{l}\text { Moderate-Severe, } \\
\mathrm{n}(\%)\end{array}$ & $5(11 \%)$ & $3(7 \%)$ & $1(2 \%)$ & $\mathrm{p}=\mathrm{N} / \mathrm{S}$ \\
\hline $\begin{array}{l}\text { Severe, } \mathrm{n}(\%) \\
\mathrm{RV} \text { function }\end{array}$ & $2(4 \%)$ & $2(4 \%)$ & $4(9 \%)$ & \\
\hline
\end{tabular}




\begin{tabular}{|c|c|c|c|c|}
\hline & Pre- & Pre-discharge & 1 to 3 months & $\begin{array}{l}\text { Pre- to } \\
\text { Pre-discharge; Pre- } \\
\text { to } 3 \text {-months }\end{array}$ \\
\hline $\begin{array}{l}\text { PASP }(\mathrm{mmHg}) \pm \\
\text { SD }\end{array}$ & $49 \pm 16$ & $44 \pm 17$ & $36 \pm 12$ & $\begin{array}{l}\mathrm{p}=0.025 \\
\mathrm{p}<0.001\end{array}$ \\
\hline $\begin{array}{l}\mathrm{RV} \text { FAC }(\%) \\
\text { mean } \pm \mathrm{SD}\end{array}$ & $28 \pm 7$ & $33 \pm 8$ & $35 \pm 9$ & $\begin{array}{l}\mathrm{p}<0.001 \\
\mathrm{p}<0.001\end{array}$ \\
\hline $\begin{array}{l}\mathrm{RV} \text { base }(\mathrm{cm}) \\
\text { mean } \pm \mathrm{SD}\end{array}$ & $4.2 \pm 0.7$ & $4.3 \pm 0.8$ & $4.4 \pm 0.8$ & $\mathrm{p}=0.460 ; \mathrm{p}=0.458$ \\
\hline $\begin{array}{l}\mathrm{RV} \text { mid }(\mathrm{cm}) \\
\text { mean } \pm \mathrm{SD}\end{array}$ & $3.6 \pm 1.0$ & $3.7 \pm 0.9$ & $3.6 \pm 1.0$ & $\mathrm{p}=0.170 ; \mathrm{p}=0.438$ \\
\hline $\begin{array}{l}\text { RV length }(\mathrm{cm}) \text {, } \\
\text { mean } \pm \mathrm{SD}\end{array}$ & $7.4 \pm 1.2$ & $6.9 \pm 1.4$ & $6.9 \pm 1.4$ & $\begin{array}{l}\mathrm{p}=0.133 \\
\mathbf{p}=\mathbf{0 . 0 3 8}\end{array}$ \\
\hline $\begin{array}{l}\text { RV FWLS (\%), } \\
\text { mean } \pm \text { SD }\end{array}$ & $-14.2 \pm 5.0$ & $-17.8 \pm 6.4$ & $-17.6 \pm 7.3$ & $\begin{array}{l}\mathbf{p}=\mathbf{0 . 0 4 7} \\
\mathrm{p}=0.162\end{array}$ \\
\hline $\begin{array}{l}\text { RVS' }(\mathrm{cm} / \mathrm{S}) \\
\text { mean } \pm \mathrm{SD}\end{array}$ & $7.4 \pm 2.6$ & $7.3 \pm 2.1$ & $8.2 \pm 2.8$ & $\mathrm{p}=0.429 ; \mathrm{p}=0.067$ \\
\hline $\begin{array}{l}\text { TAPSE }(\mathrm{cm}), \\
\text { mean } \pm \mathrm{SD}\end{array}$ & $1.0 \pm 0.3$ & $1.3 \pm 0.4$ & $1.5 \pm 0.5$ & $\begin{array}{l}\mathrm{p}=0.453 \\
\mathbf{p}=\mathbf{0 . 0 3 3}\end{array}$ \\
\hline
\end{tabular}

Abbreviations: FAC indicates fractional area change; FWLS indicates free wall longitudinal strain; LV indicates left ventricular; LVEDD indicates left ventricular end diastolic dimension; LVEDV indicates left ventricular end diastolic volume; LVEDVI indicates left ventricular end diastolic volume indexed; LVEF indicates left ventricular ejection fraction; LVESD indicates left ventricular end systolic dimension; LVESV indicates left ventricular end systolic volume; LVESVI indicates left ventricular end systolic volume indexed; MV indicates mitral valve; PASP indicates pulmonary artery systolic pressure; RV indicates right ventricular; TAPSE indicates tricuspid annular plane systolic excursion.

Table 6. Changes in LV and RV function stratified by baseline LV function

\begin{tabular}{|c|c|c|c|c|}
\hline & Pre-operative & Pre-discharge & 1 to 3 months & $\begin{array}{l}\text { Pre-operative to } \\
\text { Pre-discharge; Pre- } \\
\text { to } 3 \text {-months }\end{array}$ \\
\hline \multicolumn{5}{|l|}{$\begin{array}{l}\text { A. Severe LV } \\
\text { dysfunction } \\
(\mathrm{LVEF}<35 \%) \\
(\mathrm{N}=18)\end{array}$} \\
\hline LV EF (\%) & $30 \pm 4$ & $29 \pm 12$ & $28 \pm 12$ & $\mathrm{p}=0.63 ; \mathrm{p}=0.25$ \\
\hline $\begin{array}{l}\text { LV EDVI } \\
\left(\mathrm{mL} / \mathrm{m}^{2}\right)\end{array}$ & $102 \pm 23$ & $77 \pm 17$ & $90 \pm 47$ & $\mathbf{p}<\mathbf{0 . 0 1} ; \mathrm{p}=0.32$ \\
\hline $\begin{array}{l}\text { LV ESVI } \\
\left(\mathrm{mL} / \mathrm{m}^{2}\right)\end{array}$ & $72 \pm 18$ & $54 \pm 17$ & $68 \pm 42$ & $\mathbf{p}<\mathbf{0 . 0 1} ; \mathrm{p}=0.76$ \\
\hline $\begin{array}{l}\text { LV global } \\
\text { longitudinal } \\
\text { strain }(\%)\end{array}$ & $-9.4 \pm 3$ & $-8.5 \pm 3$ & $-7.5 \pm 6$ & $\mathrm{p}=0.24 ; \mathrm{p}=0.15$ \\
\hline $\begin{array}{l}\text { LV } \\
\text { circumferential } \\
\text { strain }(\%)\end{array}$ & $-12 \pm 3$ & $-16 \pm 9$ & $-14 \pm 7$ & $\mathrm{p}=0.70 ; \mathrm{p}=0.48$ \\
\hline $\begin{array}{l}\text { LV radial strain } \\
(\%)\end{array}$ & $7 \pm 3$ & $7 \pm 10$ & $7 \pm 12$ & $\mathrm{p}=1.0 ; \mathrm{p}=0.30$ \\
\hline
\end{tabular}




\begin{tabular}{|c|c|c|c|c|}
\hline & Pre-operative & Pre-discharge & 1 to 3 months & $\begin{array}{l}\text { Pre-operative to } \\
\text { Pre-discharge; Pre- } \\
\text { to } 3 \text {-months }\end{array}$ \\
\hline $\begin{array}{l}\text { Regurgitant } \\
\text { orifice area }\left(\mathrm{cm}^{2}\right)\end{array}$ & $0.52 \pm 0.3$ & $\mathrm{~N} / \mathrm{A}$ & $\mathrm{N} / \mathrm{A}$ & $\mathrm{N} / \mathrm{A}$ \\
\hline PASP (mmHg) & $48 \pm 14$ & $39 \pm 15$ & $32 \pm 9$ & $\mathrm{p}=0.09 ; \mathbf{p}=\mathbf{0 . 0 1}$ \\
\hline RV FAC (\%) & $25 \pm 9$ & $33 \pm 10$ & $35 \pm 11$ & $p=0.02 ; p=0.03$ \\
\hline RVFWLS (\%) & $-13 \pm 5$ & $-18 \pm 8$ & $-17 \pm 7$ & $\mathrm{p}=0.21 ; \mathrm{p}=0.08$ \\
\hline RVS' & $6.5 \pm 2.1$ & $6.9 \pm 2.2$ & $7.2 \pm 2.3$ & $\mathrm{p}=1.0 ; \mathrm{p}=0.46$ \\
\hline \multirow[t]{2}{*}{ TAPSE $(\mathrm{cm})$} & $1.3 \pm 0.5$ & $1.5 \pm 0.6$ & $1.5 \pm 0.6$ & $\mathrm{p}=0.83 ; \mathrm{p}=0.17$ \\
\hline & Pre-operative & Pre-discharge & 1 to 3 months & $\begin{array}{l}\text { Pre-operative to } \\
\text { Pre-discharge; Pre- } \\
\text { to } 3 \text {-months }\end{array}$ \\
\hline \multicolumn{5}{|l|}{$\begin{array}{l}\text { B. Moderate LV } \\
\text { dysfunction } \\
(\text { LVEF > 35\%) } \\
(\mathrm{N}=28)\end{array}$} \\
\hline LV EF (\%) & $47 \pm 7$ & $39 \pm 11$ & $41 \pm 14$ & $\mathrm{p}=0.62 ; \mathrm{p}=0.25$ \\
\hline $\begin{array}{l}\text { LV EDVI } \\
\left(\mathrm{mL} / \mathrm{m}^{2}\right)\end{array}$ & $78 \pm 20$ & $70 \pm 25$ & $57 \pm 28$ & $\mathrm{p}=0.06 ; \mathbf{p}=\mathbf{0 . 0 1}$ \\
\hline $\begin{array}{l}\text { LV ESVI } \\
\left(\mathrm{mL} / \mathrm{m}^{2}\right)\end{array}$ & $43 \pm 12$ & $41 \pm 15$ & $36 \pm 22$ & $\mathrm{p}=0.06 ; \mathbf{p}=\mathbf{0 . 0 1}$ \\
\hline $\begin{array}{l}\text { LV global } \\
\text { longitudinal } \\
\text { strain (\%) }\end{array}$ & $-10 \pm 3$ & $-10 \pm 5$ & $-9 \pm 3$ & $\mathrm{p}=0.74 ; \mathrm{p}=0.18$ \\
\hline $\begin{array}{l}\text { LV } \\
\text { circumferential } \\
\text { strain }(\%)\end{array}$ & $-15 \pm 6$ & $-16 \pm 9$ & $-14 \pm 6$ & $\mathrm{p}=0.84 ; \mathrm{p}=0.75$ \\
\hline $\begin{array}{l}\text { LV radial strain } \\
(\%)\end{array}$ & $6 \pm 6$ & $4 \pm 8$ & $6 \pm 6$ & $\mathrm{p}=0.22 ; \mathrm{p}=1.0$ \\
\hline $\begin{array}{l}\text { Regurgitant } \\
\text { orifice area }\left(\mathrm{cm}^{2}\right)\end{array}$ & $0.53 \pm 0.52$ & $\mathrm{~N} / \mathrm{A}$ & $\mathrm{N} / \mathrm{A}$ & $\mathrm{N} / \mathrm{A}$ \\
\hline PASP (mmHg) & $47 \pm 17$ & $46 \pm 17$ & $34 \pm 12$ & $\mathrm{p}=0.22 ; \mathbf{p}=\mathbf{0 . 0 1}$ \\
\hline RV FAC (\%) & $29 \pm 5$ & $33 \pm 7$ & $35 \pm 8$ & $\mathrm{p}=0.01 ; \mathrm{p}=0.01$ \\
\hline RVFWLS (\%) & $-15 \pm 5$ & $-18 \pm 7$ & $-18 \pm 8$ & $\mathrm{p}=0.62 ; \mathrm{p}=0.36$ \\
\hline RVS' & $7.9 \pm 2.8$ & $9.0 \pm 3.0$ & $9.0 \pm 2.9$ & $\mathrm{p}=0.69 ; \mathrm{p}=0.16$ \\
\hline TAPSE (cm) & $1.4 \pm 0.4$ & $1.5 \pm 0.4$ & $1.5 \pm 0.4$ & $\mathrm{p}=0.65 ; \mathrm{p}=0.26$ \\
\hline
\end{tabular}

Abbreviations: FAC indicates fractional area change; FWLS indicates free wall longitudinal strain; LV indicates left ventricular; LVEDVI indicates left ventricular end diastolic volume indexed; LVESVI indicates left ventricular end systolic volume indexed; RV indicates right ventricular; LVEF indicates left ventricular ejection fraction; MV indicates mitral valve; N/A = not applicable; PASP indicates pulmonary artery systolic pressure; RV indicates right ventricular; TAPSE indicates tricuspid annular plane systolic excursion; TR indicates tricuspid regurgitation. 

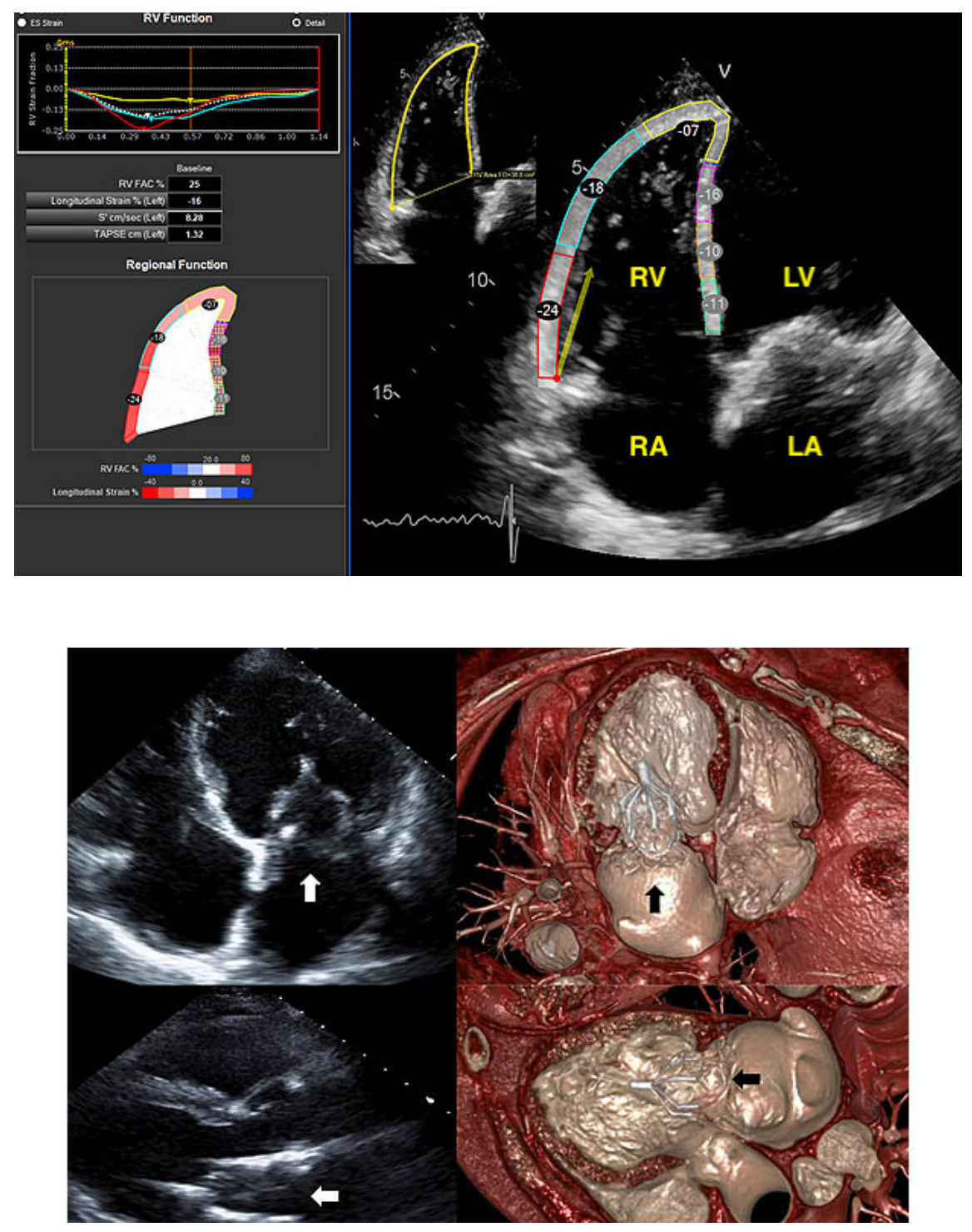

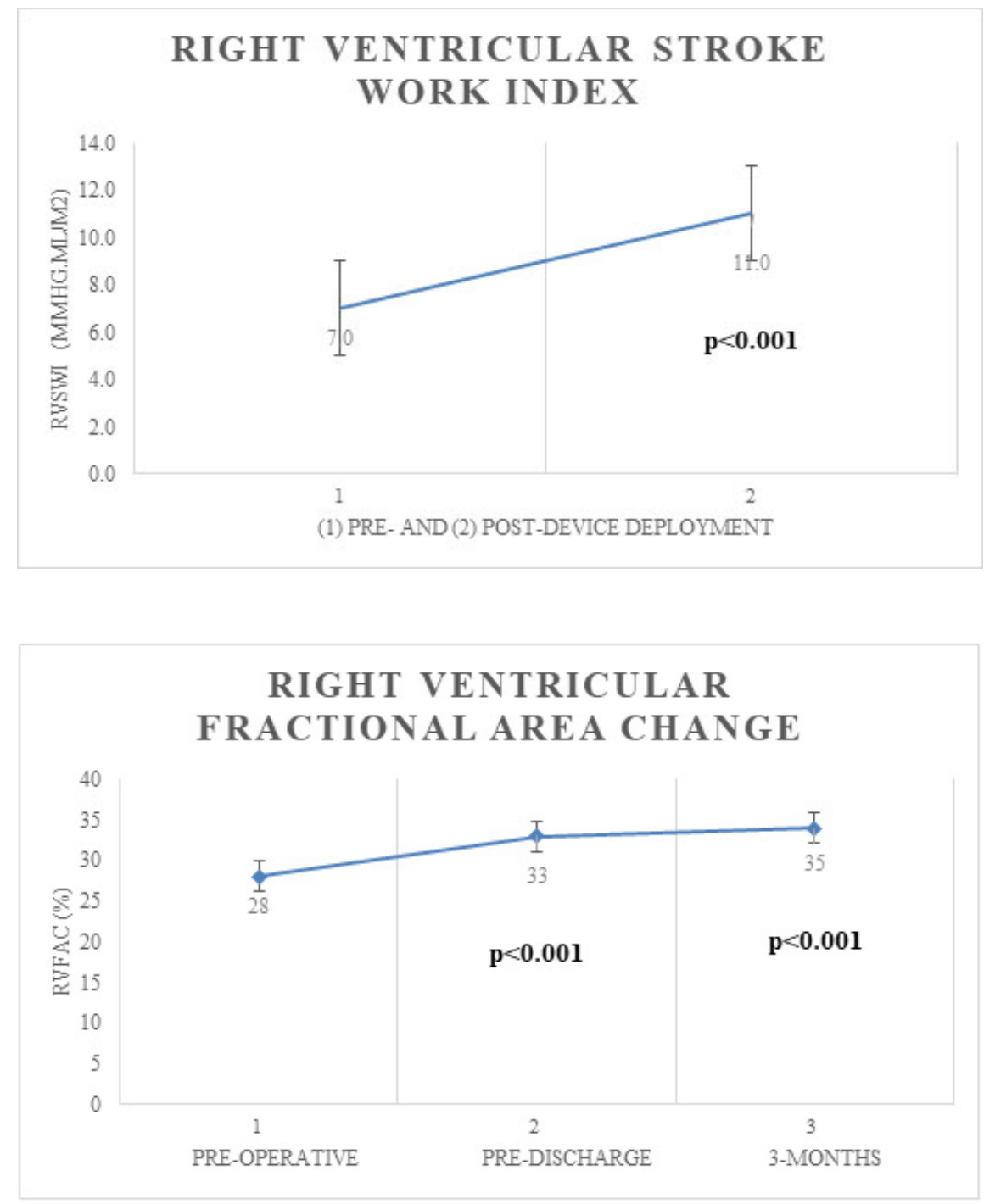

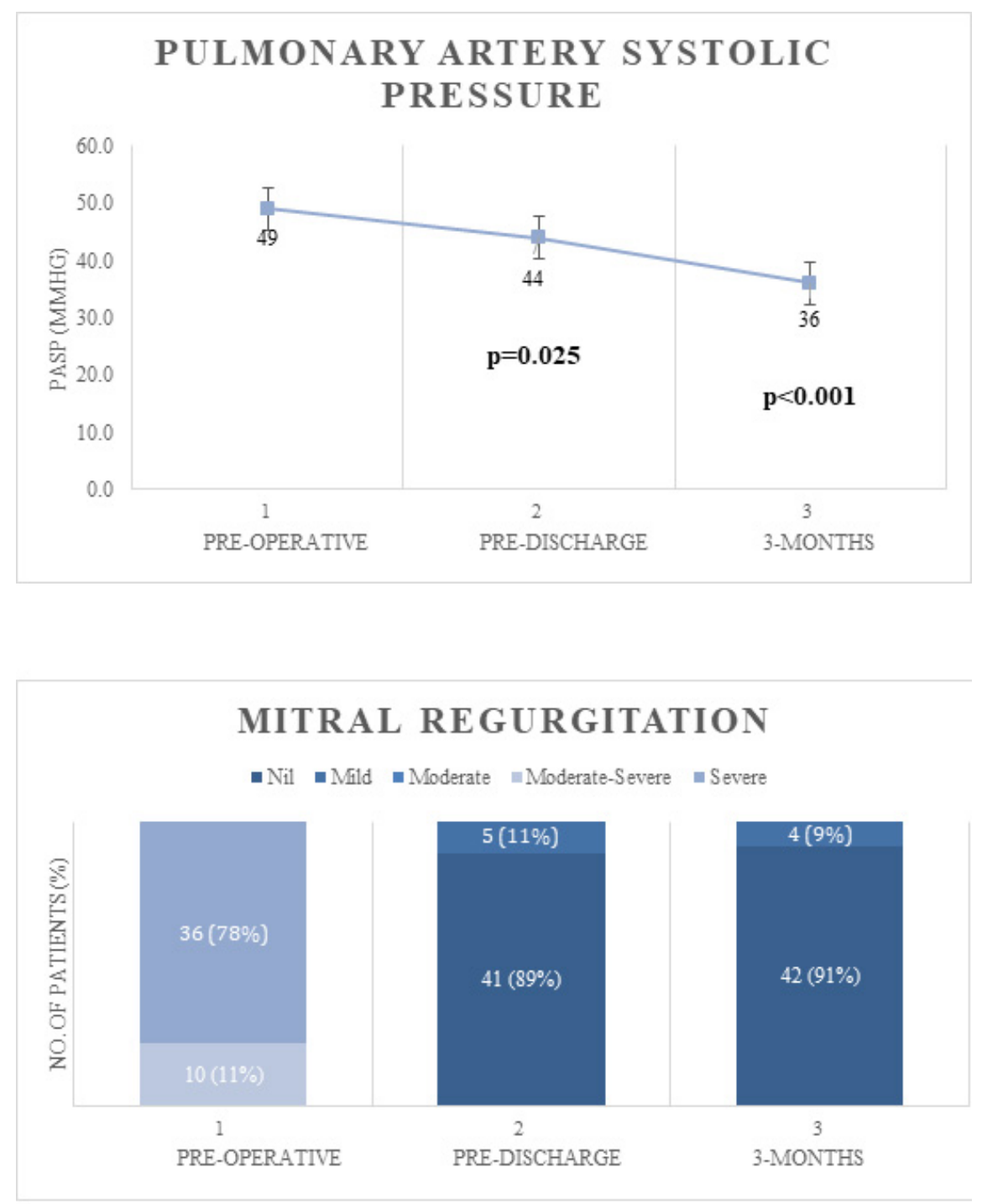


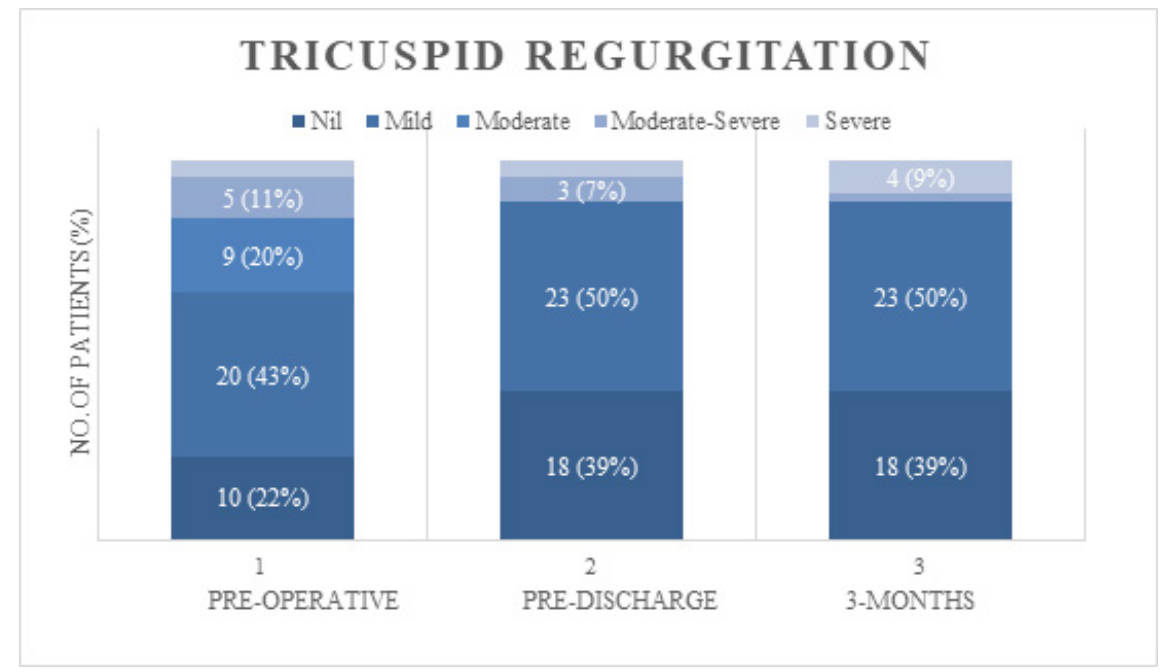

LEFT VENTRICULAR VOLUMES

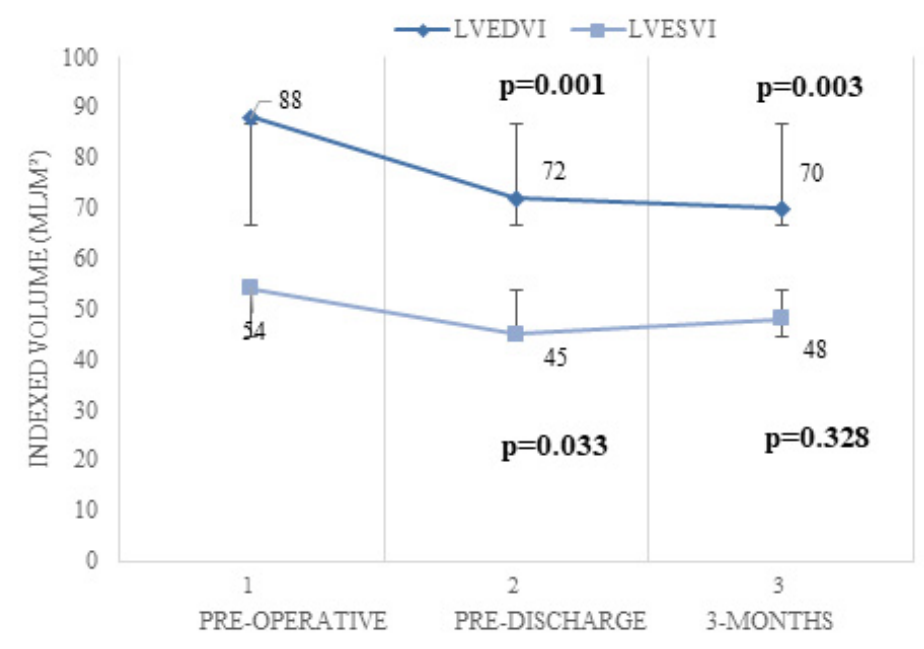




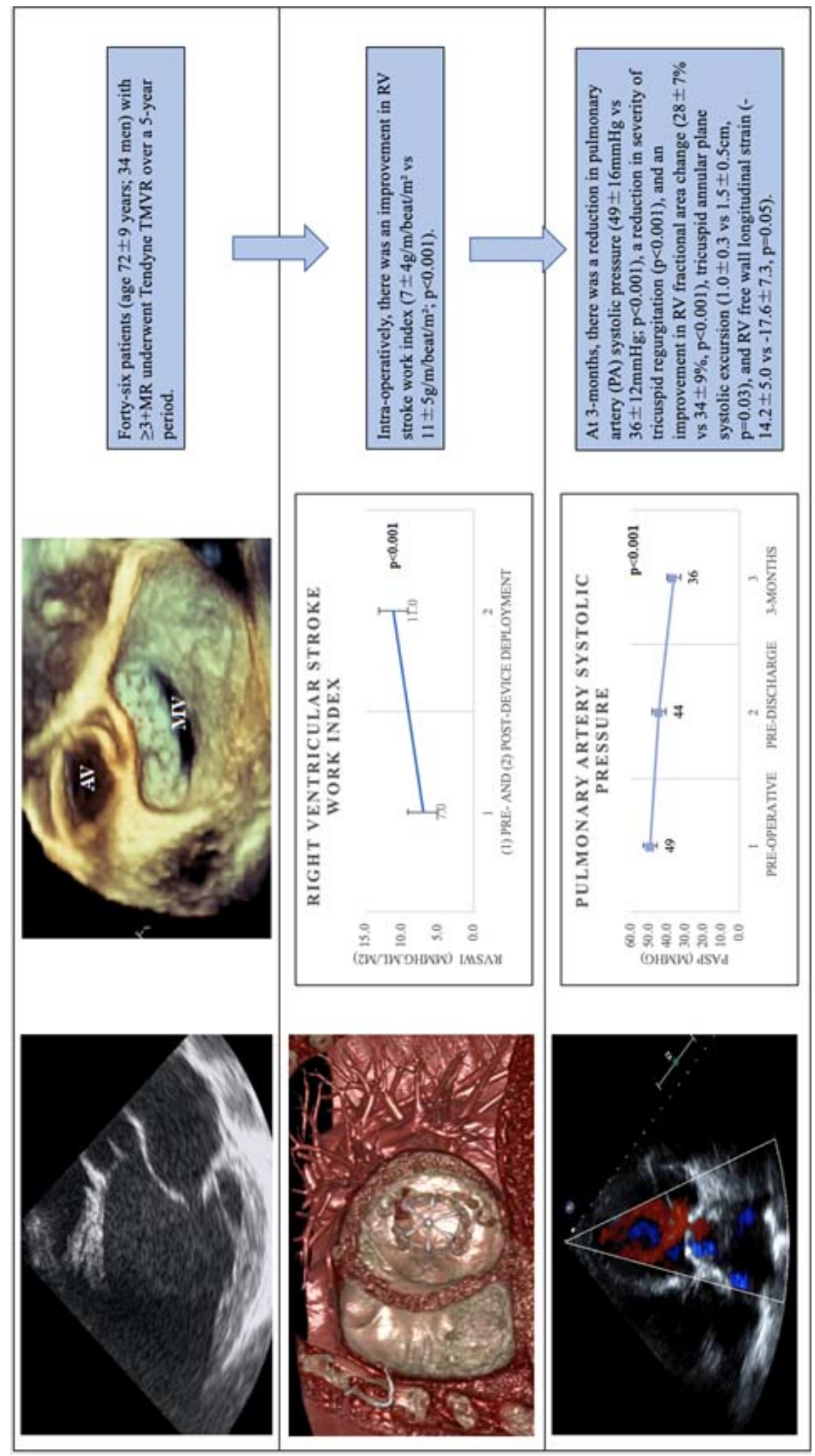

